Marketing in Asia Group

\title{
Negotiating Travel Constraints via Technology: A Study of Malay Muslim Women through a Hierarchical Constraint Model Perspective
}

\author{
Senutha Poopale Ratthinan \\ Centre for Research on Women and Gender (KANITA) \\ Nor Hafizah Selamat \\ Centre for Research on Women and Gender (KANITA) \\ School of Social Sciences, Universiti Sains Malaysia, Penang, Malaysia
}

\begin{abstract}
As a moderate Muslim nation, the mobility of Malay Muslim women in Malaysia is not legally restricted by the state. However, their movements are constrained by factors such as their roles, responsibilities, and the need to preserve values related to their religious and custom requirements. These constraints are shaped by patriarchal gender norms where women are expected to be obedient to a system of institutionalized male power. Our paper seeks to understand the constraints subjected to Malay Muslim women in travelling for leisure and study how they negotiate those constraints using technology. Based on ten qualitative, in-depth interviews conducted with Malay Muslim women aged between 22 to 37 years old, the findings showed that women are gaining the support, trust and freedom to travel via technology. Using the Hierarchical Constraint Model, the findings indicate that culture is significant wherein several constraints faced by MMW differ from those faced by Western or other Asian women. The new insights generated from this paper are unique as they reflect on the unexplored segment of Asian women where Malay Muslim women are becoming the testament of transformation. The finding indicates their departure from the gendered patriarchy norms as technology becomes their tool to negotiate constraints while facilitating the growth of female travel market. A significant association between travel constraints and negotiation illustrates that women are empowered by using technology to travel.
\end{abstract}

Keywords: Malay Muslim Women, Travel Constraints, Technology, Negotiation, Hierarchical Constraint Model 


\section{Introduction}

This study aims to address a lacuna tacitly resisting the gendered patriarchy norm in Malaysian leisure landscape concerning Malay Muslim women (MMW). The departure is assisted by technology which becomes their tool for negotiation. Young Muslim women between the ages of 18 and 39 in Southeast Asia are described as an influential group in travel and tech-savvy while being religiously observant (JWT Intelligence, 2017). Majority of these young Muslimah travel for leisure, with a third of the women saying they go overseas at least once a year. The Halal Travel Frontier 2018 highlighted that one of the top trends that will continue to rise is the female Muslim millennial travellers market. The report indicates that apart from travelling, these Muslim women also play a huge role in inspiring and empowering others to travel by sharing their experiences and stories through blogs, social media or travel websites.

Looking at the academic pursuit on Asian gender and tourism, recent research substantiates the multiple identities of women including Malay women who negotiate their many roles within the boundaries of socio-cultural norms and religious parameters to reflect their participation in travel (Khoo-Lattimore \& Mura 2016; Yang, Khoo-Lattimore \& Arcodia, 2017; Khoo-Lattimore \& Wilson, 2017; Ying, Khairil \& Jamil, 2017; Khoo-Lattimore \& Gibson, 2018). The numerous research helps to highlight the need to study and understand the Asian perspective by focusing on constraints associated with the respective community. Given the heterogeneity of women travellers, travel constraints vary according to their social background or gender norms that influence opportunities and actions. Constraints are integral when individuals decide to travel and it refers to aspects that hinder participation in leisure even though the freedom and desire exist (Jackson, 1988, Raymore, 2002). Asian women's role as tourists were invisible in tourism anthropology until the late 1990s (Adams, 2016) with much of the tourism anthropology literatures highlighting the conditions and role of women as hosts reflecting socio-economy or entrepreneurship development, employment constraints, sex tourism and impression on indigenous women (Benthall, 1988; Mason, 1999; Milgram, 2001; Selamat, Aziz \& Endut, 2015).

Now that women are travelling actively, tourism anthropology in Asia should focus on better understanding the contemporary dynamics of women's travel experiences by analysing the impact of the cultural constraints they face (Reiter, 1975). By doing so, strategies used by women collectively and individually to enlarge their leisure could be explored (Foley, 2005). In an Asian setting, the norms and rules governing social behaviour tend to ensure that certain outcomes are reproduced without any apparent exercise of agency, apart from compliance with the rules (Kabeer, 1999). Unless questioned or negotiated, the failure to achieve their desire reflects some deep-seated constraint identified as a manifestation of disempowerment. While the statistic of Malay Muslim women travelling shows an increase, studies to look into the specific area such as the constraints faced by them are still lacking. Travel constraints can tacitly contribute to persistent gender disparities despite MMW's increased access to economic opportunities and resources, Technological transformations in travel industry somewhat enabled Malay Muslim women to negotiate or counter stereotypical norms. As Scott \& Frew (2014) claim the omnipresence of technology in tourism has benefitted travellers to enhance their experience. A recent study by Suhaimi \& Lokman (2018) analysed the requirement and proposed a design concept 
for a suitable mobile application that will significantly assist Muslim women tourist. This study is directed towards evaluating the relationship between travel constraints subjected to Malay Muslim women and how they negotiate the constraints using technology.

\section{Literature Review}

\section{Hierarchical Constraint Model}

Hierarchical Constraint Model (HCM) was proposed by Crawford and Godbey's in 1987 which employs three categories that consist of intrapersonal, interpersonal and structural constraint. Intrapersonal constraints relate to psychological conditions such as insecurity and fear that hinder an individual from travelling while interpersonal constraints are barriers from social interactions with family, friends or society. Structural constraints refer to issues that halt participation in travel such as lack of time, finance or access to information. In 1991, Crawford, Jackson, and Godbey expanded the model by proposing that three components will be encountered in a hierarchical sequence whereby individuals negotiate and overcome intrapersonal constraints before moderating the interpersonal and structural constraints. In their anthropological study, Chick and Dong (2003) revised the HCM model to put cultural and structural constraints prior to intrapersonal and interpersonal constraints because behaviour is constrained by one's culture, where their decisions are strongly influenced, if not strictly determined. Therefore, this study underlines culture as a significant constraint category that substantially enhances the validity of the HCM model when applied to cross-cultural societies. Assessing the HCM theory after two decades, Godbey et al. (2010) call for future research to explore the effects of relevant moderators in shaping perceptions of constraints and negotiation processes with increased opportunities for women's pursuit of non-traditional leisure. A critical assessment of a specific cultural group in specific activity requires considering the nature of constraints and negotiation strategies that are being used. This study extends the pursuit of Gao and Kerstetter (2016) who address the validity of the HCM framework and its associated negotiation strategies in an Asian context. Given that most studies on leisure constraints were focused on Western-centric research paradigm, the findings of this study focuses on the Asian perspective by empirically demonstrating the influence of culture among MMW in Malaysia.

Evolution of travel is accompanied by emerging challenges to confront. Numerous scholars have debated about constraints in leisure studies. Wilson \& Little (2005) showed that although women are free to travel, they may be constrained by social and gendered settings. Defined as aspects which prevent an act of travel, constraints post affect women's capacity to start, maintain or increase travel and/or negatively affect their quality of travel (Hung \& Petrick, 2010). Khan (2011) suggests that in leisure, women remain relatively more constrained than men. She adds that due to economic and social changes, urban women may longer be disadvantaged in travel, however 'doing gender' poses restrictions on the freedom of women. A growing body of knowledge on travel constraints related to women also shed some light on experiences by women from different subgroups specifically Asian women (Wilson \& Little, 2005; Khan, 2011; Khoo-Lattimore \& Mura, 2016; Yang \& Arcodia, 2015; KhooLattimore \& Wilson, 2017). Shifting the focus on a diverse background of Asian 
women, cultural factors such as religion and traditional values seem to enforce distinct travel constraints. Thus, it is crucial to note that access to resources and decreased societal pressure does not guarantee or open up opportunities for MMW to travel. For Muslim women, travelling with likeminded women or with family was the only option to travel while guaranteeing her Islamic values (Jouili, 2015). In Malaysia, mobility of MMW is not legally restricted by the state. However, their movements are constrained by other factors such as their gender roles and responsibilities, gaining approval or else support from their guardians, the need to preserve values related to their religion and custom besides being safe when travelling.

Most of these constraints are shaped by patriarchal gender norms embedded in cultural obligations where women are expected to obey a system of institutionalized male power. Abdullah and Wok (2008) found present Malay women are caught in a dilemma between the modern challenges of life and traditions. Discussing Asian gendered identities in tourism, Yang and Mura (2016) highlighted that the study by Asbollah et al. (2013) confirms the influence of societal and religious constraints on Muslim women's travel behaviour. However, they challenged the study by Kim et al. (2015) for lacking an in-depth analysis of the reason behind women's decision when choosing the type of travel to engage in. Their argument further stressed Asian scholars are confined by stereotypical images of men and women. Livengood \& Stodolska (2004, p.187) found that 'constraints are not insuperable obstacles to participation, but rather that they can be successfully negotiated.' Negotiation refers to measures women take and strategize to tackle travel constraints. Constraints need to be negotiated successfully to ensure participation in leisure, and it is heavily dependent on negotiating multiple factors that must be overcome (Crawford et al., 1991; Scott, 1991). Masika and Bailur (2015) found that women from India and Uganda are not passively accepting socio-cultural norms as they negotiate the use of technology through processes of adaptive preferences and patriarchal bargaining within the set of concrete constraints. It appears that one-way MMW has been exercising their negotiation skill to overcome travel constraints are via technology. By understanding the constraints of MMW, it will help to better comprehend the scope of negotiation using technology. Deriving from Jackson and Rucks (1995), negotiation involves both reasoning as well as behavioural strategies. In Islam, negotiation is a positive tool to foster, strengthen or facilitate bonds of warmth and cooperation. The three concepts of negotiation in Islam namely reconciliation (sulh), discussion and communication (Ramdani et al., 2016) provided the platform for arguments within religious parameters. It says

Invite to the way of Allah swt with wisdom and good instruction, and argue with them in a way that is best. Indeed, your Lord is most knowing of who has strayed from His way, and He is most knowing of who is [rightly] guided.

(Surah An-Nahl, 16:125)

On the other hand, Islamic teachings are fundamental and dominant in the Malay customs which have influenced MMW's actions in performing daily activities (Jamil Osman, 2013). According to Zakaria (1980), patriarchal beliefs remain strong in Malaysia among Malay families where men still hold the decision-making authority, while women continue to be in charge of the household and family. Islam and the 
Malay customary law (adat) is regarded as two important factors to better understand the multiple identity constructions of MMW. Understanding the influence of religion and Malay customs will give clarity about the constraints as well as the negotiation measures taken by the MMW.

\section{Malay Muslim Women (MMW)}

When discussing the identity of Malay Muslim Women (MMW), the assertion can be divided into two, the early and modern phase. Studies characterized MMW in the early days as marginalised, weak and easily manipulated (Hashim \& Hamdan, 2010) where their identity is determined by sex and labour (Syed Hassan \& Ramli, 1998) that showed women's muted presence between the 16th and 18th centuries. Although a handful of MWW was seen as freedom fighters and participated in political front from Che Siti Wan Kembang to Ibu Zain, Khadijah Sidek, Shamsiah Fakeh and Fatimah Hashim, their existence in the public sphere was acknowledge particularly only after independence (Mohamad, 2002). Post-independence, access to education and employment was better for MWW however Ackerman (1991) defines the ideal modern Malay women as modest middle- or working-class women who focus on the domestic household in their lives with minimal or no notion of socializing. Mobility for rural or urban MMW was limited for the purpose of employment or education. Leisure meant visiting family and friends. Travelling for personal pleasure was linked to social status as well as financial stability. After the 1960s, a number of MMW travelled overseas for education and employment purposes. As more women pursue education and engage in contemporary skilled sectors with waged employment, they became economically and socially stable. Advanced technologies, migration from rural to urban areas, pro-women policies and the development of educational plus employment opportunities increased the mobility and presence of MMW in the public sphere (Ahmad, 1998; Abdullah et al., 2008). Zaini and Rahman (2006) suggest that the participation of women in the public sphere shifted gender roles in the traditional family system wherein typically man holds the breadwinner position and the woman is a housewife. With shared responsibilities, men's approach to domestic responsibilities has improved.

According to Karim (1992), the meaning of power relationship in short and long term for Malay men and women is defined by the participation in decision making and expressing autonomy within and across spheres of activity. Mouser (2007) indicated that in Malay Muslim patriarchal society, gender constructions and performances of Malay women are often perceived by outside researchers as 'shrouded under a veil' of increasing Islamic opposition. Being a MMW, the Malay-Islamic identification has become the most crucial symbolic element of identity that Geertz (1963) posits are crucial elements in the formation of ethnic identity. As Islam and local Malay custom (adat) are embedded in MWW identity, they are seen as submissive and selfless. For Michael Peletz (1995) Malay customary laws (adat) itself defines gendered spaces. Roziah Omar and Azizah Hamzah (2003, p.117) pointed out the discrepancy in a woman's professional space and her domestic space: where MMW still holds strongly to her role as the dutiful daughter, wife or mother despite the fact that she is educated, financially independent and holds an important position in the public domain. Jamil Osman (2013) in her study suggests that modern MMW are expected to adhere to religious obligations, Malay customary laws and traditional values which are reinforced by the old patriarchal ideology. She adds that they negotiate Islamic 
teachings, the Malay customary laws, social conventions and their surroundings while maintaining their image as modern women. Therefore, MWW uses technology as a tool to negotiate their travel constraints and enjoy leisure.

\section{Technology as a Negotiation Tool}

Technology today has transformed the traditional way of travel planning with more flexibility and customer-oriented services (Buhalis \& Law, 2008; Del Chiappa, 2011; Tribe \& Liburd, 2016; Ratthinan \& Selamat, 2017). Various hardware, software, and NetWare like smartphones, websites, apps or broadband available these days enable travellers to search, study and select travel information anywhere anytime (Konwiser, 2012). Technology empowers travellers by allowing them two-way information and interactions ( $\mathrm{Yu}$ et al., 2014). According to the report by the Ministry of Communications and Multimedia, there are 20.1 million active Malaysian internet users in 2015, contrary to 1995 when only one in every thousand Malaysians had access to the internet. Malaysia's broadband penetration rate in 2015 of $72.2 \%$ shows the rising trend towards a digital lifestyle. Anuar, Musa and Khalid (2014) found that as mobile penetration rates rise, studies were conducted to explore the adoption of technology in the Malaysia tourism industry. A study by Hashim (2007) revealed the multiple identities of MMW as a wife, mother and social netizen through their engagement and participation online which had significant positive effects on internet usage among the MMW in Malaysia. In the same way, Yusof (2009) in her study demonstrated the ways in which a modem Malay woman uses the blog as a tool of empowerment to negotiate her many roles within the boundaries of socio-cultural norms and religious parameters. This was substantiated by Hashim et al. (2011) who explored MMW turning to virtual spaces as a mean to be heard. They discussed weblogs becoming a tool of empowerment by women negotiating the gender norms, cultural practices and religious way of life. In their recent study about intention to use technology among Malaysians, Ting et al. (2016) found that Malays are more inclined to comply with what their families and peers do because they are concerned with social relationships and receiving approval from others. Despite the changing pattern in the MWW's social interaction for travel gusto, the very little study can be found to address the role of technology and travel in their life. Although Ying et al. (2017) found that the differences of West and Asia values are not a constraint for Malaysian women to travel where most millennial women travel with the convenience of technology advancement, Asian and MMW considers their cultural characteristics, conditions and choices before negotiating the constraints to change the status quo. However, the majority of the existing research focused on the influence of travel and technology in relation to women without giving due attention to the cultural aspects as well as the reasons behind their action. This, in particular, varies depending on the different subgroups of women, in this case, MMW.

\section{Research Methodology}

\section{Data Collection}

This study adopted the qualitative and interpretive paradigm in which data was derived from the results of the doctoral ethnographic fieldwork. The cross-cultural setting from an interpretive ontological perspective deems that multiple realities exist, 
constructed through lived experiences and shaped by the meaning attached to the truth (Denzin, 1997; Jamal \& Hollinshead, 2001). Therefore, interpretive paradigm best captures the social reality where women negotiate the constraints and conditions surrounding travel using technology. The research focuses on examining the experiences of MMW, their background, constraints in travelling and usage of technology as a tool of negotiation. Contemporary ethnography method was used to gather data on women's experiences about their travel constraints and negotiation strategies (Small, 1999; Tribe, 2001). The aim was to discover and explore as many facets of the MMW experiences by interacting with them, listening to them and sharing time with them in an informal setting. Wolcott (1981) suggests that ethnography in anthropology helps to strengthen cross-cultural standpoint. The study employed contemporary ethnography approach of 'step-in-step-out' proposed by Madden (2010) which separates the immersed participation of classic ethnography towards an 'inter-subjective embodiment', as "the ethnographer's body needs to acquire some competence relevant to the participants he or she is working with" (p.83). As suggested by Frohlick and Harrison (2008) when researching any individual engaging in travel activities, ethnographic imagination requires flexibility. Graburn (2002) posits that ethnography of tourists is contemporary ethnography which O'Reilly (2012) described as reflexive and conducted in full awareness of the myriad limitations associated with humans studying other human lives. In light of this methodological knowledge that explores the constraints plus the negotiation strategies, semi-structured interview (Small, 1999) was used to enable a rich interview in a short period of time, in an open, conversational way with a focus on a set of predefined questions (Merton et al., 1990). Interviews were carried out around Georgetown, Penang. As the capital city of Penang, it is well known for its colonial past, historical buildings, heritage trails, food multicultural community and masses of travellers. Participants that fit the criteria of the study were selected using a purposive sampling technique (Neuman, 1997). Before each interview, participants were asked to provide tacit consent by reading and signing a consent form in addition to the audio recording of verbal consent to ensure trustworthiness and voluntary participation. A copy of the form that contains details of the research and the researcher was provided to the participants. The interview started with questions about their background, experiences of travelling and personal travel stories. It was followed by questions about their views on religion and identity as a MMW in relation to travelling, constraints faced and the role of technology in negotiating those constraints. To provide confidentiality, pseudonyms were used.

\section{Data Analysis}

All the interviews were audio-recorded and transcribed verbatim for coding and thematic analysis. Using the five-step qualitative analysis process suggested by Patton (1990) themes emerging from the data was carefully verified. The qualitative data analysis computer software NVivo10 facilitated the coding process by recording, sorting, relating and retrieving the codes as required. In addition, the coding frequencies derived from the narratives helped in the process of thematic analysis (Kuckartz, 2014). General categories and themes were formed to label the data collected. It was important to grasp the inherent and explicit cultural meanings the women attach to religion and cultural aspects of life as it mirrors their gender role expectations, social status and perception towards travel. Finally, the data were summarised and presented as the results of this paper. To ensure that the data was 
accurate, external sources relevant to the matters of the local Malaysian Muslim communities were reviewed in order to help in assessing the reliability of the qualitative data (Livengood \& Stodolska, 2004). Holloway and Shipway (2010) suggest that triangulation in ethnographic qualitative research is within-method rather than between methods with different ideologies. During the interview session, member checks were carried out verbally so the participants were able to agree, adjust or expand their original response which in a way enhances the validity of the findings. According to Carlson (2010), member checking is used to understand a phenomenon by validating or clarifying the meaning with participants by posting a question such as is this you meant? All the audio interviews were transcribed in detail, to capture the holistic views and meanings in the conversations. Following suggestion by Carlson (2010) that participants be given an alternative to deciding how they would like to obtain the transcript document, we explained and requested for their email addresses when gaining the tacit consent. A copy of the verbatim transcript was emailed to the participants for checking. It is to give participants the opportunity to validate the accuracy of the findings while serving as a means to counterbalance concerns about the adequacy of understanding based on limited time of exposure. In the email, each participant was asked to read the transcripts and give feedback whether it resonated with the experience they shared or if there was anything they would like to alter. Researchers allowed one week for participants to respond. All the participants responded with broad agreement. Madden (2010, p.25) posits that 'validity and reliability are built upon the construction of thoughtful and appropriate methodologies.' Tacit consent from participants and triangulation of methods adopted by this research is an indication that interpretive qualitative research is reliable both in art and science. One of the main arguments against reliability in relation to ethnographic research is the fact that it is conducted in a natural setting and focuses on the process. This is to confirm that the research findings reflect the experiences, meanings and accounts of the participants. According to Spradley and McCurdy (1972), ethnography which differs from positivistic research is defined by anthropologists as an analytic description of an intact cultural scene. Therefore, to address the validity and reliability issue, detailed coverage of the research methodology consisting of data collection and analysis provided ensures proper research practices have been followed.

\section{Results}

Being conscious of the assorted group of MMW in Malaysia and to avoid making a general assumption, this paper focuses on the urban, middle class, educated and financially stable MMW. The rationale for choosing this group rest in the fact that one-third of a thousand urban, middle-class Malaysian women aged 18 to 39 surveyed in the New Muslimah: South-East Asia Focus Report have travelled overseas at least once a year (JWT Intelligence, 2017). Narratives of ten urban MMW who were travelling around Georgetown, Penang was analysed for the purpose of this paper. The small sample size used resonates with the concern to gain a deep understanding of a phenomenon centered on this particular subject. All the participants were Malaysians, aged between 22 to 37 years old. Three of the participants were married meanwhile the rest seven were single. Four of them were students while six of the participants had stable jobs. Most of the MMW interviewed indicated that they travel with family or friends. Only three of the participants experienced solo travelling. All 
the participants owned smartphones, were tech-savvy and stated that religion is an important aspect of their life. The table below summarizes the details of the participants participated in the study.

Table 1: Details of Participants

\begin{tabular}{|c|c|c|c|c|c|}
\hline Pseudonym & $\begin{array}{l}\text { Marital } \\
\text { Status }\end{array}$ & Age & Occupation & $\begin{array}{c}\text { Preferred Type } \\
\text { of Travel }\end{array}$ & $\begin{array}{c}\text { Top } 3 \text { Most Used Travel } \\
\text { Apps }\end{array}$ \\
\hline Aina & Single & 22 & Student & Family / Friends & $\begin{array}{l}\text { TripAdvisor, Skyscanner, } \\
\text { Google maps }\end{array}$ \\
\hline Aley & Single & 33 & Civil Servant & Solo / Friends & Agoda, Expedia, Waze \\
\hline $\mathrm{Az}$ & Married & 30 & Accountant & Family & $\begin{array}{l}\text { Waze, Airasia, Google } \\
\text { maps }\end{array}$ \\
\hline Fae & Single & 34 & $\begin{array}{l}\text { Assistant } \\
\text { Engineer }\end{array}$ & Solo / Friends & $\begin{array}{l}\text { Skyscanner, Booking.com, } \\
\text { TripAdvisor }\end{array}$ \\
\hline Jue & Single & 37 & Civil Servant & Solo / Family & $\begin{array}{l}\text { Google maps, Kiblat, } \\
\text { TripAdvisor }\end{array}$ \\
\hline Kay & Single & 22 & Student & Friends / Family & $\begin{array}{ll}\begin{array}{l}\text { Trivago, } \\
\text { TripAdvisor }\end{array} & \text { Skyscanner, } \\
\end{array}$ \\
\hline Lady & Single & 31 & Finance Officer & Family / Friends & $\begin{array}{l}\text { Google maps, Waze, } \\
\text { TripAdvisor }\end{array}$ \\
\hline $\mathrm{Nad}$ & Single & 22 & Student & Family / Friends & $\begin{array}{l}\text { Booking.com, Sky scanner, } \\
\text { Google maps }\end{array}$ \\
\hline Nur & Married & 27 & Postgraduate & Family & $\begin{array}{l}\text { Google Maps, Agoda, } \\
\text { Grab }\end{array}$ \\
\hline Sha & Married & 25 & $\begin{array}{l}\text { Office } \\
\text { Administrator }\end{array}$ & Solo / Family & $\begin{array}{l}\text { Skyscanner, } \\
\text { TripCase }\end{array}$ \\
\hline
\end{tabular}

The findings of this study are presented in two main sections. The first part examines the constraints experienced by MMW and the extent it influences their travel choices. The second part discusses the strategies they employed to negotiate the constraints using technology.

\section{Travel Constraints - "I want to travel but..."}

After deliberating the aspects that influence travel activities of MMW, we realized that the context in which modern MMW function encompasses Islam, Malay customs and the contemporary demand for women to engage actively in economic and social affairs. This paper discusses the constraint based on intrapersonal, interpersonal and structural conditions using the framework proposed by Crawford and Godbey (1987). We agree with Chick and Dong (2003) that cultural aspect is embedded in all three intrapersonal, interpersonal and structural constraints because MMW's behaviour is constrained by culture as their decisions are strongly influenced, if not strictly determined by it. The constraints identified in this paper are interlinked to these gendered expectations and patriarchal system ingrained in the background of MMW. While Mouser (2007) claim that urban MMW is advantageously altering, transforming and utilising the views placed upon them by religion, ethnicity or modernity, Jamil Osman (2013) explains that identity of MMW still adheres to specific gendered expectations both in the private and public spheres. 


\section{Safety}

Women are extra concerned about personal safety compared to men when travelling. All the participants of this study highlighted safety as a key travel constraint. Aine, aged 22, a student and a novice traveller, explicitly described safety was her major concern by stating

"...women are likely to be restricted because of some issues specifically security and safety of the destination It is so unfortunate that even at this modern era, there are so many crimes committed against female travellers, proving that travelling can cause an untoward incident. This does not only worry me but also my parents'

The issue of safety creates fear in women which halts them from travelling. It was important for the participants to ensure safety before being confident to embark on any travel activity. Safety influences the decisions MMW make about the travel type, destination and itineraries, wherein the quality of travel experience is determined. After the 9-11 incidents, Islamophobia and misconceptions towards Islam grew and created further concerns for women particularly travelling wearing a hijab. MMW fear travelling to destinations which lacks awareness about Islam or posts prejudices against Islam and Muslims. Women's sense of safety in the public sphere is incredibly complex with multiple factors that exert power over women which affect their behaviour accordingly (Karusala \& Kumar, 2017). Their insecurities about safety constantly create reservations for women travel outside their comfort zone. Most of the time, MMW fear the unexpected situations such as sexual harassments or attacks on personal safety during their travel which ultimately influences the destination choices and eliminate them from enjoying their trip (Wilson \& Little, 2005; Heimtun \& Abelsen, 2014).

\section{Religious Requirements}

Religious tenets and customary laws require MMW to gain permission from guardians, normally their parents or husband before they participate in any activities outside their home (Othman, 2006). MMW are confined in a cultural bubble where their travel behaviour is constrained by certain religious as well as cultural requirements (Asbollah et al., 2013). Compared to other travellers, MMW travellers are concerned about adhering to religious requirements such as consuming halal food and performing prayer when travelling. Therefore, they prefer to travel to destinations that offer Muslim friendly facilities. In Islam, the existing travel concession for Muslims considers them as a musafir, allowing them to shorten or combine their prayers. Given that it is a sin to abandon prayers, MMW travellers need to find proper prayer facilities when planning to travel. Unlike Malaysia, some mosques abroad only offer prayer facilities for men. That leaves women without a proper place or facilities to perform prayers. Being an enthusiastic young Muslim woman, Nad always wanted to travel around Europe but she shared her concerns

'...I can pack Maggi or Brahims and survive while travelling but I still had doubts about places I can perform my prayer. It is also difficult to take wuduk (ablution) in European toilets.' 
Besides enjoying the view and interacting with locals, travellers also seek to experience the selection of food in countries they visit as it is one of the best ways to discover and enjoy a country. Thus, being able to find halal food in the destination will be an added advantage. For blogger, foodie and student traveller, Kay, one of the challenging part of her travel is '...finding local but halal food. Not being able to taste it makes my trip less meaningful. Not all destinations provide or even know about halal food."

Muslim travellers become sensitive when consuming products or services abroad before they ensure that it is halal compliant. In her seminal work 'Deciphering a Meal', anthropologist Douglas (1972) proposed tourism businesses to look into other cultures to understand their rules on what can and can't be consumed. Therefore, the increasing demand for Muslim-friendly facilities besides halal compliant products and services 'have encouraged new opportunities for the expansion of hospitality provision' (Stephenson, 2014, p.162). Thus, the need for a proper understanding of the constraints of religious requirements concerning MMW's travel decisions became crucial.

\section{Roles and Responsibilities}

The roles and responsibilities of MMW depict a major part in making decisions about travel. In Malay society, women's contribution to domestic roles will be extended into the formal public sphere through rituals or ceremonies derived from customary laws (Karim, 1992). This in return reflects in them gaining support or approval from the family, friends and society. Abdullah et al., (2008) explored the roles and responsibilities of MMW and they found that women first adhere to their traditional cultural values as a strong mother, a good daughter and subservient wife. Only then, they can be motivated to pursue equal career opportunity or leisure as men, without feeling guilty of forsaking their responsibilities. Therefore, women encounter constraints to leisure while attempting to perform their roles and duties in the best possible way. Noor (2003) posits that employed women are usually stressed and struggle with role conflict when faced with dual responsibilities of family and office work where travel is rarely an option. When given an option between family and leisure, MMW tends to choose family matters compared to self-fulfillment. Modern MMW is trapped in managing the challenges of life set against the parameters of religion and customary laws. Being married for more than nine years now, Nur shares the burden of her roles as a mother, wife and full-time postgraduate student

"...with my studies and managing my family, it is always difficult to
allocate time for other leisure activities. I have to oversee my son's
school matters and take care of my toddler. My husband helps but being
a mother, I have the tendency to look after everything. It is my
responsibility. I feel guilty leaving my children to travel"

Married women like Nur, finds it hard to cope with the guilt they feel for not being with their kids when travelling. As a working mother, Az hates leaving her son when asked to go outstation for official work saying “...it's the most excruciating feeling, he always looks at me with those sad eyes, I wish I could just quit my job. I guess this is the sacrifice of being a working mom." Working women are expected to be responsible for the family and to maintain the traditional expectation of being a 
woman in Malay culture. For the singletons, apart from their work or study responsibilities, they need to uphold their roles as a daughter and sister in the family. Nobaya and Abdullah (2013) described this as being sandwiched between their roles as a daughter, mother, wife, employee and caregiver to the elderly. MMW chances to enjoy leisure is limited while coping with the demands of their roles and responsibilities.

\section{Gaining Support and Approval}

An additional constraint faced by MMW is gaining support from the family, friends, workplace and society to travel. MMW needs approval and support from their family to travel. For single MMW, the approval comes from their parents or guardians. On the other hand, according to Noor (2001) in the Malay matrimonial context, when a woman gets married, she is obligated to gain approval and care for her husband and also his family beside her own family. Another major challenge is the lack of support offered by the workplace or community. Noor (2001) adds that MMW is forced to cope with the demands of family obligations and workplace pressure. Fae shared that “...my family is religious, I am too. My family never prohibited me from travelling but I have to ensure them that I will be safe and that I can take care of myself abroad before I get their approval" Being a filial daughter requires MMW abiding the obligations of gaining the consent from their respective guardians before engaging in any activities. Similarly, Sha disclosed that besides gaining approval and support from her husband and family members, she has to make sure that her work is not affected.

'...who doesn't love to travel, me too! I am lucky to be married to a man who loves to travel. My in-laws are also okay. But both of us need to think a lot before making any arrangements to travel. We both work. So we plan according to our work schedule. I cannot afford to leave everything at work and go for a break.'

\section{Time and Money Matters}

Despite being single or married, MMW struggles with time and money. On one hand, they have to manage time according to their roles and responsibilities. On the other hand, they have financial responsibilities towards their parents, family and personal expense or savings (Salih, 1994). MMW copes with double roles and makes sacrifices to maintain a balance in life. While doing this, leisure becomes secondary and almost non-existent. Aley views travel as a reward "I work hard like slave and travel is my time-out phase. But I must plan well because being a civil servant, I cannot afford to just take off from work." Leading her busy life as a student, Nad explicitly revealed that time and money are concerns when she thinks about travelling

'... as a student, I have to manage my time between studies, family and also curricular activities. My student loan is also limited so money is another factor I think about before I travel. So, you see travelling for me is not easy and needs a lot of consideration.'

Scholars like Henderson (1991, 1997) and Shaw et al., (1991) highlighted the need to seek and understand hidden nuances behind the lack of time and money. The finding of this paper showed that MMW considers finance and time as an important essence 
that influences travel because they need to cater to their primary needs. In Malay culture, men as head of the family usually handle finances meanwhile, women have limited purchasing power and not expected to make responsible financial decisions for their own wellbeing. Wilson and Little (2005) describe this as the type of constraint that relates specifically to the functional and practical challenges that limit travel experiences for women.

\section{Lack of Travel Information}

One other limitation faced by MMW is lack of travel knowledge. Women need to be equipped with information before or during travel. Lack of travel knowledge impedes travel planning. It makes MMW vulnerable and anxious to embark on a journey, creating concerns for their guardians as well. As a Sabahan, Lady was anxious travelling to Peninsular Malaysia "...I have never been there before. it is in Malaysia but still, I was nervous because the culture here [Penang/Peninsular] and Sabah is somewhat different. The same when I want to travel to other places". Contrary to visiting families, relatives or friends, the need for detailed pre-travel information is crucial when travelling for leisure. Anticipated factors such as the atmosphere, people, security, language, food, weather and other aspects are important when making travel decisions or planning. Familiarity and knowledge about travel destination also help to increase the self-confidence to travel. According to Fodness and Murray (1997), travelling becomes more satisfying when uncertainty is reduced with enhanced destination knowledge. Given the fact that information plays a crucial part in determining the choices and help throughout the making decision process, women need to acquire or search for information to travel (Osti, Turner \& King, 2009). Previously, Meyers-Levy (1988) and Kim et al. (2007) found that women processed information by resorting more to sources in the external world rather than to their own judgments. For instance, they attached higher values to a wider variety of both online and offline information sources while choosing travel destinations. Without information, women feel uncertain about travelling and it becomes a constraint which limits their mobility.

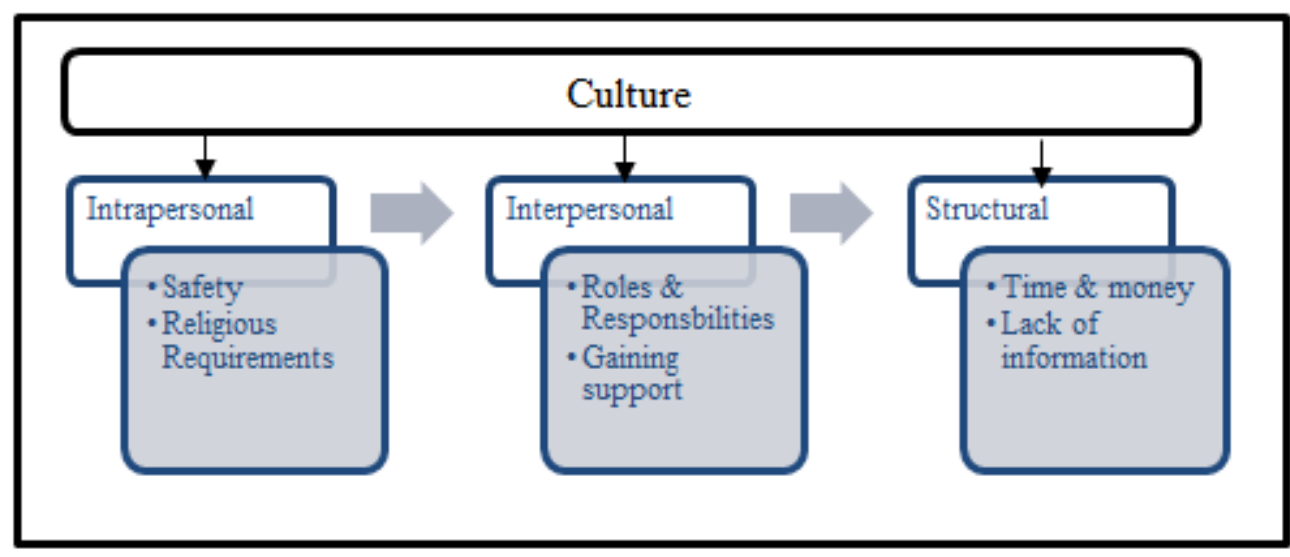

Figure 1: Travel Constraints

Source: Refined from Crawford \& Godbey (1987) and Chick \& Dong (2003) 


\section{Negotiating Travel Constraints via Technology}

Scott (1991) found that individuals will find ways to adjust or negotiate the challenges to pursue and participate in leisure. The next part of this paper discusses how MMW negotiates travel constraints using technology and adds on to the proposition that participation in leisure depends on negotiation measures (Jackson et al., 1993). Jackson et al. (1993, p.9) stated that 'the initiation and outcome of the negotiation process are dependent on the relative strength of, and interactions between, constraints on participating in an activity and motivations for such participation'. Both Scott (1991) and Jackson et al. (1993) suggest that negotiation strategies are individual driven where thoughts and actions are modified. The findings of this study show that MMW is gaining the support and freedom to travel by bargaining the constraints using technology. The three negotiation categories found were making informed choices, creating conviction and practical planning.

\section{Making Informed Choices}

Firstly, MMW dissolves their constraints regarding safety and religious requirements by making informed choices. Safety is a key concern for MMW to ensure that it is safe for them to travel. This means MMW's decision to travel is based on information made after deliberating and understanding the expected consequences of making that choice. Huang et al. (2016) indicated that the existence of technology provides an opportunity for travellers to explore different information of travel such as the safety aspect, accessibility, and available facilities and evaluate whether it fits their requirement. Experiences shared by fellow Muslim women and other travellers online become an influential medium to counter anxieties about safety and religious requirements. In this case, MMW gains assurance to travel as technology play a central role in facilitating and ensuring that they make a reliable decision. Aina explained in her story

'...Japan was my first trip outside Malaysia. My sister and I got all the information online and planned our trip using technology. I don't feel being female is an obstacle anymore for travelling because with technology. I have the assurance of safety and what to avoid. Reviews online from other female travellers or Muslim ladies are also very important and helpful for me. Japan was very Muslim friendly and there is a lot of information online about where to find halal food, mosques and so on. The travel application does not only make me a better traveller but also gives me the confidence to travel. Personally, I will only enjoy travelling if I am confident.'

MMW like Aina needs reliable source and valid information that is consistent with their values or religious requirements to make informed choices. For example, concerns about Muslim friendly and halal compliant services as well as products. Destinations like Malaysia, Indonesia, Japan and Taiwan have been forefront providers of halal and Muslim friendly services. By making informed choices, MMW increases their confidence while overcoming their anxieties. MMW has the freedom to deliberate about the choices related to travel information with technology. The growing number of travel apps, blogs plus Muslim centred travel websites such as 
www.havehalalwilltravel.com or www.halaltrip.com provides an opportunity for MMW to negotiate their intrapersonal constraints. After resolving their intrapersonal constraints, MMW negotiates the interpersonal barriers to create conviction by managing their roles and responsibilities besides gaining trust from family, friends and society using technology.

\section{Creating Conviction}

Subsequent to gaining clarity and deciding to travel, MMW faces another burden in the form of their roles and responsibility. Technology provides MMW with the flexibility to make a travel plan and manage their everyday errands at the same time. Asbollah et al. (2013) in her study found that MMW prefers to travel with family rather than travelling solo. Majority of the participants in this study shared similar views. Nur, who balances her familial role while pursuing her postgraduate studies, depends on technology to ensure that she can travel without neglecting her role as a dutiful wife, mother and student. Referring to her Penang trip, she explains,

'...I struggle managing household chores, the kids and studying at the same time. My husband helps but it does not mean the weight of my duties lessens. When we travel, my husband relies on me to plan. Luckily, technology helps me to manage everything. I can do all my work and also take time off to travel. I was able to plan this trip while I was writing my thesis. Multitasking, you know.'

Women have always been better at multitasking as they take care of family, home and work commitments as a routine. The demands of their role and responsibilities encourage MMW to negotiate using technology. They are able to manage the burden effectively and plan according to their preference. Besides that, technology enables MMW to maintain symbolic proximity with their family and friends while establishing a sense of presence while absent in an attempt to gain support from the family, friends, workplace and society. Jue expressed "Before I travel, I will always share my travel plans with my parents. During my travel, I keep in touch with them via WhatsApp and video call. My parents trust that I will not tarnish their trust and my identity as a Muslim girl." For women like Nur, Jue and the rest of MMW participated in this study, the importance placed upon religion and role requirements resulted in modifying their actions towards coping and finding alternate measures to negotiate the constraints.

\section{Practical Planning}

Besides looking for time and money saving deals, MMW needs to obtain knowledge pertaining to travel. For instance, millenials are offered student rate or discounts. In addition to offering affordable competitive prices, technology also saves time as MMW is restrained by daily obligations. Multiple travel applications, websites or blogs give recommendations, reviews and rates as a source of reference in preparation for travel. Kay remarked 


\begin{abstract}
'...with my busy schedule and life as a student, money and time is my biggest barrier. But with technology, various apps like Skyscanner and Trivago, I can save money and time. I can create my travel itineraries, book tickets, book hotel and get info about a place sitting on my bed. Info is also real-time and not outdated, so it is valid. I can also read reviews from other travellers for a referral.'
\end{abstract}

Married woman Az added that "... with my busy schedule and little kid, I don't want to go to the airport and wait in line just to book a ticket. I'd rather buy my tickets via the AirAsia app. It saves time and its way cheaper too". It was also clear that MMW benefits gaining information from reliable sources such as local tourism authorities, websites and applications or by reading reviews of fellow female travellers. Technology offers MMW valuable information in making informed choices besides creating conviction while facilitating practical travel planning.

\title{
Discussion
}

Whilst technology had become the backbone that is changing the nature of the travel experience and customer behaviour, it is important to understand how that's shifting women's role identities, needs and priorities as travellers particularly those confined by social-cultural norms. Travel choices, constraints, negotiation and motivation are interrelated. In this paper, we argued that MMW has autonomy grounded by their education employment and financial stability. However, they remained subdued by religious requirement and Malay customary laws. In the Malay culture, the identities of MMW are often defined within familial roles emphasizing their position as a member of that culture. McCall and Simmons (1978) found that in Malay culture, women are expected to follow the societal norms. When faced with travel constraints women needed to negotiate their stance within their identity as MMW and the patriarchal system ingrained in their culture. Despite being actively negotiating their travel constraints, MMW still abides by the practices of Islamic teachings and the Malay adat or customary law. Both are fundamental and dominant in the lives of MMW. By understanding the Islamic teachings and the Malay adat, MMW navigates and negotiate the constraints faced by them. A significant association between travel constraints and negotiation shows women are empowered by using technology to travel. A growing number of MMW participating in travel using technology shows that the stereotype mindset associated with MMW is changing. Furthermore, several online travel resources such as travel blogs and Muslim specified travel websites have empowered MMW to transform into anything that they want. The emerging contents online on MMW travel as an important source of information shaping travel decisions exhibit technology as a tool of negotiation and empowerment for any MMW interested in travelling. The finding of this paper is a clear indication of the departure of MMW from the gendered patriarchy norms as technology becomes their tool to negotiate and facilitate the growth of female travel market. Being MMW required them to mediate matters not just through the lens of religion, but also Malay customary law (adat). Technology as a mediator plays a greater role as MMW find convenient solutions from affordable travel bookings to accessible travel reviews. Ultimately traditional Muslim ventures have also embraced the digital transformation. The stories MMW shared in this study revealed both about their travel and faith 
dimensions. They push the boundaries and initiate measures to traverse the limitations.

\section{Managerial Implications}

Today women are seeking a journey on their own, a realization of travel as an important personal reality in their lives. With the growth of heterogeneous women travellers and technology-enhanced travel experiences, it is crucial for tourism stakeholders and businesses to focus on creating a significant shift towards initiatives that will be able to enhance the potential of this development. Looking at how MMW negotiate the constraints via technology, stakeholders should build products or services emphasising on the negotiation strategies by introducing new or upgrading existing technological design to match efficient usage patterns that cater for the need of Muslim female travellers. Technology provides MMW with the opportunity to negotiate travel constraints while they learn more about their self, religion and the outside world. Across Malaysia and Southeast Asia, the rising swathe of potential Muslim women travellers is emerging. From singles to married, baby boomers to millenials, it is a huge market to be tapped on. As MMW travellers expect faith-based needs, they seek a reliable medium to retain their trust and confidence. The proliferation of technologically savvy MMW shows that pre-travel planning is made via online travel applications. The rampant trend prompts travel providers to be attentive to current travel conditions by targeting the need for instant, real-time seamless access to information and communication.

\section{Further Research Directions}

This study is an attempt to extend the scholarly pursuit of tourism scholars who evaluate the behaviour of women using the gender lens particularly Asian women (Henderson 2016; Khoo-Lattimore \& Mura, 2016; Yang, Khoo-Lattimore \& Arcodia, 2017; Khoo-Lattimore \& Wilson, 2017; Ying, Khairil \& Jamil, 2017; Khoo-Lattimore \& Gibson, 2018). Extending the quest by Chick and Dong (2003), Godbey et al. (2010), Gao \& Kerstetter (2016) and Suhaimi \& Lokman (2018), we explored the role of technology in the negotiation efforts by MMW to overcome travel constraints. It is an alternative interpretation of the travel behaviour of women governed by religious doxa and Malay customary law (adat). Different from the augmented western-centric gender and tourism discourse, this study provides an ethnocentric critic from the perspective of MMW that will fill the gap in the existing anthropological Asian tourism scholarship. The findings of this study addressed the ambiguity in tourism research of the women 'voices' and 'choices 'to signify their experiences of negotiating travel constraints with technology and its link to their sense of empowerment. It stresses the influence of culture which is embedded in all three constraint elements. This substantially 'enhance the validity of the model when it is applied to other societies or whenever culture cannot be assumed to be a constant' (Chick \& Dong, 2003, p.343). Future research could seek to unveil other substantial aspects surrounding the identity of culturally sanctioned women related to travelling and the role of technology as a form of liberation from their typical identities. Finally, it contributes to understanding the importance of gender, technology and the condition of 'being' a woman traveller in the 21 st century in influencing their choices, decisions 
also travel experiences and thereby contribute to the deconstruction of firmly rooted stereotypes.

\section{References}

Abdullah, H., Anuar, N. A. M., Mahadi, M. S. M., Zaidi, M. Z., \& Azmi, F. Y., (2016), Travel constraints affecting young tourist travelling domestically, In Sumarjan, N., Mohd, R. S., Zurinawati, M., Sukyadi, D., Mohd, H. M. H., Suryadi, K., \& Purnawarman, P., (2016), Heritage, culture and society: Research agenda and best practices in the hospitality and tourism industry, CRC Press.

Abdullah, K., Noor, N. M., \& Wok, S., (2008), The perceptions of women's roles and progress: A study of Malay women, Social Indicators Research, vol. 89, no. 3, pp. 439-455.

Ahmad, A., (1998), "Country briefing paper on women in Malaysia", Retrieved from www.adb.org/.../books/.../women_in_malaysia/women_malaysia.pdf

Ahmad, N., \& Abdullah, H., (2013), Malaysian women and their role as the sandwiched generation, Pertanika Journal of Social Sciences \& Humanities, vol. 21, no. 1, pp. 147-162.

Alamgir, A., (2014), Islam and women's rights: Discourses in Malaysia, ProcediaSocialand Behavioral Sciences, vol. 114, pp. 872-876.

Asbollah, A. Z., Michael, E. J., \& Lade, C., (2012), Muslim women tourist behaviour: The spiritual gaze, Proceedings of the 22nd Annual Conference, La Trobe University.

Buhalis, D, \& Law, R., (2008), Progress in information technology and tourism management: 20 years on and 10 years after the internet - the state of etourism research, Tourism Management, vol. 29, no. 8, pp. 609-623.

Chick, G., \& Dong, E., (2003), Possibility of refining the hierarchical model of leisure constraints through cross-cultural research, Paper presented at the Northeastern Recreation Research Symposium, Newtown Square, PA.

Crawford, D. W., Jackson, E. L., \& Godbey, G., (1991), A hierarchical model of leisure constraints, Leisure Sciences, vol. 13, no. 4, pp. 309-320.

Del Chiappa, G., (2011), Trustworthiness of Travel 2.0 applications and their influence on tourist behavior: An empirical investigation in Italy. In Low, R., Fuchs, M., \& Ricci, F., (2011), Information and Communication Technologies in Tourism, Vienna, Austria, Springer.

Denzin, N. K., (1997), Interpretive ethnography: Ethnographic practices for the 21st century, Sage Publications.

Gao, J., \& Kerstetter, D. L., (2016), Using an intersectionality perspective to uncover older Chinese female's perceived travel constraints and negotiation strategies, Tourism Management,vol. 57, pp. 128-138.

Godbey, G., Crawford, D. W., \& Shen, X. S., (2010), Assessing hierarchical leisure constraints theory after two decades, Journal of Leisure Research, vol. 42, no. 1, pp. 111-134.

Hashim, R. S., Jaafar, Z., Ho-Abdullah, I., \& Yusof, N. M., (2011), Computer mediated communication and gendered presentation of selves, International Journal of Soft Computing, vol. 6, no. 5, pp. 143-151.

Hashim, R. S., (2007), Blogs of their own: A story of two Malaysian women bloggers. 3L: language, linguistics and literature, The Southeast Asian Journal of English Language Studies, vol. 13, pp. 127-142.

Hashim, R. S., \& Hamdan, S. I., (2010), Facets of women in Malay romance fiction, Kunapipi, vol. 32, no. 1, p. 8. 
Holloway, I., Brown, L., \& Shipway, R., (2010), Meaning not measurement: Using ethnography to bring a deeper understanding to the participant experience of festivals and events, International Journal of Event and Festival Management, vol. 1, no. 1, pp. 74-85.

Hua, L. Y., Ramayah, T., Ping, T. A., \& Cheah, J-H., (2017), Social media as a tool to help select tourism destinations: The case of Malaysia, Information Systems Management, vol. 34, no. 3, pp. 265-279.

Huang, Y. C., Backman, K. F., Backman, S. J., \& Chang, L. L., (2016), Exploring the implications of virtual reality technology in tourism marketing: An integrated researc framework, International Journal of Tourism Research, vol. 18, no. 2, pp. 116-128.

Hung, K., \& Petrick, J. F., (2010), Developing a measurement scale for constraints to cruising, Annals of Tourism Research, vol. 37, no. 1, pp. 206-228.

Ibrahim, R., (2016)., "What is wrong with me?"- Single women's reflections on missing the marriage transition, Asian Social Science, vol. 12, no. 12, pp. 213-219.

Jackson, E. L., (1988), Leisure constraints: A survey of past research, Leisure Sciences, vol. 10, no. 2, pp. 203-215.

Jackson, E. L., \& Rucks, V. C., (1995), Negotiation of leisure constraints by junior high and high-school students: An exploratory study, Journal of Leisure Research, vol. 27, no. 1 , pp. 85-105.

Jamil Osman, Z., (2013), Malay muslim academic women in dual-career families: Negotiating religious and cultural identities and practices, Doctoral dissertation, University of York.

Jouili, J. S., (2015), Pious practice and secular constraints: Women in the Islamic revival in Europe, Stanford University Press.

JWT Intelligence, (2017), "The new muslimah: Southeast Asia focus", Retrieved from https://www.jwtintelligence.com/2017/09/new-muslimah-southeast-asia-focus

Kabeer, N., (2016), Gender equality, economic growth, and women's agency: The "endless variety" and "monotonous similarity" of patriarchal constraints, Feminist Economics, vol. 22, no. 1, pp. 295-321.

Kandiyoti, D., (1988), Bargaining with patriarchy, Gender \& Society, vol. 2, no. 3, pp. 274290.

Karusala, N., \& Kumar, N., (2017), Women's safety in public spaces: Examining the efficacy of panic buttons in New Delhi, In Proceedings of the 2017 CHI Conference on Human Factors in Computing Systems, pp. 3340-3351.

Karim, W. J. B., (1992), Women and culture: Between Malay adat and Islam, Westview Pr.

Khan, S., (2011), Gendered leisure: Are women more constrained in travel for leisure, Tourismos, vol. 6, no. 1, pp. 105-121.

Khoo-Lattimore, C., \& Prayag, G., (2018), Understanding Asian and Western women on girlfriend getaways: The relationship between motivation and accommodation performance, Journal of Hospitality Marketing \& Management, vol. 27, no. 2, pp. 239-259.

Khoo-Lattimore, C., \& Wilson, E., (2017), Women and travel: Historical and contemporary perspectives, CRC Press.

Kim, S., Im, H. H., \& King, B. E., (2015), Muslim travelers in Asia: The destination preferences and brand perceptions of Malaysian tourists, Journal of Vacation Marketing, vol. 21, no. 1, pp. 3-21.

Kim, D. Y., Lehto, X. Y., \& Morrison, A. M., (2007), Gender differences in online travel information search: Implications for marketing communications on the internet, Tourism Management, vol. 28, no. 2, pp. 423-433.

Konwiser, E., (2012), "Introducing managed travel 2.0, a revolution in corporate travel that will affect everyone", Retrieved from http://www.tnooz.com/article/introducingmanaged-travel-2-0-a-revolution-in-corporate-travelthat-will-affect-everyone

Livengood, J. S., \& Stodolska, M., (2004), The effects of discrimination and constraints negotiation on leisure behaviour of American Muslims in the post-September 11 America, Journal of Leisure Research, vol. 36, no. 2, pp. 183-208. 
Mason, M., (2010), Sample size and saturation in $\mathrm{PhD}$ studies using qualitative interviews, Qualitative Social Research, vol. 11, no. 3.

McCall, G. J., \& Simmons, J. L., (1978), Identities and interactions: An examination of human associations in everyday life, The Free Press.

Mohamad, M., (2002), At the centre and the periphery: The contributions of women's movements to democratization, in Wah, F. L. K., \& Teik, K. B., Democracy in malaysia, discourses and practices, Curzon Press.

Mouser, A. E., (2007)., Defining 'Modern'Malay womanhood and the coexistent messages of the veil, Religion, vol. 37, no. 2, pp. 164-174.

Noor, N. M., (2001), Work, family and well-being: Challenges of contemporary Malaysian women, IIUM Press.

Noor, N. M., (2003), Work- and family-role experiences, work-family conflict and women's well-being: Some observations, Community, Work and Family, vol. 6, pp. 297-319.

Omar, R., (2003), Negotiating their visibility: The lives of educated and married Malay women, In Omar, R., \& Hamzah, A., (2003), Women in Malaysia: Breaking boundaries, Utusan Publications and Distributors Sdn. Bhd

Osti, L., Turner, L. W., \& King, B., (2009), Cultural differences in travel guidebooks information search, Journal of Vacation Marketing, vol. 15, no. 1, pp. 63-78.

Peletz, M. G., (1995), Neither reasonable nor responsible: Contrasting representations of masculinity in Malay society, In Ong, A., \& Peletz, M. G., (1995), Bewitching women, pious men: Gender and body politics in Southeast Asia, The University of California Press.

Ramdani, A., Mohammed, R., \& Ahmad, M. K., (2016), The concept of negotiation from the islam perspective (in the islamic organization), The Social Sciences, vol. 11, no. 20, pp. 4790-4800.

Ratthinan, S. P., \& Selamat, N. H., (2017), Understanding the push and pull motivational factors of technology usage for traveling among women students in USM, Penang, Journal of Information, vol. 2, no. 4, pp. 52-63.

Raymore, L. A., (2002), Facilitators to leisure, Journal of Leisure Research, vol. 34, no. 1, pp. 37-51.

Ridgeway, C. L., \& Correll, S. J., (2004), Unpacking the gender system a theoretical perspective on gender beliefs and social relations, Gender \& Society, vol. 18, no. 4, pp. 510-531.

Salman, A., \& Hasim, M. S., (2009), sustainability of internet usage: A study among malay women in a suburban setting in Malaysia, European Journal of Social Sciences, vol. 9, no. 3, pp. 433-447.

Salih, M. N. Z., (1994), Women: Reasons for working, housewife and attitude, In Ismail, Y., (1994), Muslim women in Organisation: A Malaysian perspective, A.S. Nordeen.

Scott, D., (1991), The problematic nature of participation in contract bridge: A qualitative study of group-related constraints, Leisure Sciences, vol. 13, pp. 321-336.

Scott, M. M., \& Frew, A. J., (2014), Adoption of information and communication technology (ICT) by in-trip leisure tourists, In Tourists' behaviors and evaluations, Emerald Group Publishing Limited.

Shafaei, F., (2017), The relationship between involvement with travelling to Islamic destinations and Islamic brand equity: A case of Muslim tourists in Malaysia, Asia Pacific Journal of Tourism Research, vol. 22, no. 3, pp. 255-271.

Syed Hassan, S. Z., Ramli, R., (1998), Kedudukan dan citra wanita dalam sumber-sumber tradisional melayu, institut alam dan tamadun melayu, UKM, Bangi.

Shaw, S. M., (1994), Gender, leisure, and constraint: Towards a framework for the analysis of women's leisure, Journal of Leisure Research,vol. 26, no. 1, pp. 8-22.

Seow, D., \& Brown, L., (2018), The solo female Asian tourist, Current Issues in Tourism, vol. 21, no. 10, pp. 1-20.

Stephenson, M. L., (2014), Deciphering 'Islamic hospitality': Developments, challenges and opportunities, Tourism Management, vol. 40, pp. 155-164. 
Stivens, M., (2006), 'Family values' and Islamic revival: Gender, rights and state moral projects in Malaysia, Women's Studies International Forum, vol. 29, no. 4, pp. 354367.

Suhaimi, A. N. M., \& Lokman, A. M., (2018), A Kansei approach to investigate mobile apps requirements for muslim women tourist, In International Conference on Kansei Engineering \& Emotion Research, Springer, Singapore.

Ting, H., Yacob, Y., Liew, L., \& Lau, W. M., (2016), Intention to use mobile payment system: A case of developing market by ethnicity, Procedia-Social and Behavioral Sciences, vol. 224, pp. 368-375.

Tribe, J., \& Liburd, J. J., (2016), The tourism knowledge system, Annals of Tourism Research, vol. 57, pp. 44-61.

Wilson, E., \& Little, D. E., (2005), A "relative escape"? The impact of constraints on women who travel solo, Tourism Review International, vol. 9, no. 2, pp. 155-175.

Yang, E., Khoo-Lattimore, C., \& Arcodia, C., (2015), Asian women, solo travel: A conceptual framework of risk in the gendered and cultured tourism context, CAUTHE 2015, Gold Coast, Australia.

Yang, E. C. L., \& Mura, P., (2016), Asian gendered identities, In Khoo-Lattimore, C., \& Mura, P., (2016), Asian genders in tourism, Channel View Publications.

Yang, E. C. L., Khoo-Lattimore, C., \& Arcodia, C., (2017), A narrative review of Asia female travellers: Looking into the future through the past, Current Issues in Tourism, vol. 20, no. 10 , pp. 1008-1027.

Yang, E. C. L., Khoo-Lattimore, C., \& Arcodia, C., (2018), Power and empowerment: How Asian solo female travellers perceive and negotiate risks, Tourism Management, vol. 68, pp. 32-45.

Ying, T., Khairil, W. A., \& Jamil, B., (2017), Generation Y Malaysian women's perception towards solo travel, Asia-Pacific Journal of Innovation in Hospitality and Tourism, vol. 6, no. 2, pp. 45-54.

Yu, G., Carlsson, C., \& Zou, D., (2014), Exploring the influence of user-generated content factors on the behavioral intentions of travel consumers, In Proceedings of the 25th Australasian Conference on Information Systems, 8th - 10th December, Auckland, New Zealand.

Yusof, N. M., (2009), Re-inventing the self: Constructions of identity in Malaysian blogosphere, The Southeast Asian Journal of English Language Studies, vol. 15, pp. $125-142$.

Zakaria, M., (1980), Sikap dan nilai masyarakat mengenai pergerakan wanita (The society's attitude and value of women's movement), Dewan Budaya. 